\title{
Role of Measurement of Placental Thickness and Diameter at the Third Trimester Using Two Dimensional Ultrasound in Determination of Low Birth Weight
}

\author{
Ahmed Hassan Hamdy ${ }^{1, *}$ MB BCh, Ali Osama Al Saeed ${ }^{1}$ MD, Taher Mohammed Mostafa ${ }^{1}$ MD \\ and Bassem Ragab Abdel-Aziz ${ }^{1}$ MD
}

\author{
* Corresponding Author: \\ Hamdy, Ahmed Hassan \\ dr.a7md80@gmail.com \\ Received for publication \\ December 29, 2019; accepted \\ February 18, 2020; Published \\ online March 5, 2020.
}

Copyright 2020 The Authors published by Al-Azhar University, Faculty of Medicine, Cairo, Egypt. All rights reserved. This an openaccess article distributed under the legal terms, where it is permissible to download and share the work provided it is properly cited. The work cannot be changed in any way or used commercially.

doi:10.21608/aimj.2020.21674.1041

${ }^{1}$ Obstetrics and Gynecology Department, Faculty of Medicine, Al-Azhar University Cairo, Egypt.

\begin{abstract}
Background: Birth weight is the first weight of the fetus or newborn obtained after birth preferably measured within the first hour of life before significant postnatal weight loss has occurred.

Aim of the work: This study was conducted to assess the role of measurement of placental thickness and diameter in the third trimester using two-dimensional ultrasound in the determination of low birth weight.

Patient and methods: This study was conducted between 15 October 2019 and 10 June 2019 at Sayed Galal University Hospital and Damanhour Teaching Hospital. The study was carried on "400" uncomplicated pregnant women who attended the outpatient clinic at Sayed Galal University Hospital and Damanhour Teaching Hospital, two-dimensional ultrasound measurement of placental thickness and diameter was done to assess its role in the determination of low birth weight.

Results: The results of this study show that there were significant positive correlations between neonatal weight and GA, Placental diameter, Placental thickness, Biparietal diameter, Femur length \& Abdominal circumference $(\mathrm{P}<0.05)$, while there was no statistically significant difference regarding maternal age $(\mathrm{P}>0.05)$. Also, our results show that there was no statistically significant difference according to parity regarding fetal and placental measures. The results show that there was no statistically significant difference according to fetal sex regarding placental measures $(\mathrm{P}>0.05)$.

Conclusion: The result of this study shows a strong positive correlation between neonatal weight and placental thickness, so placental thickness measured at the level of umbilical cord insertion can be used as an accurate sonographic indicator in the assessment of fetal weight.
\end{abstract}

Keywords: Placental Thickness and Diameter; Two Dimensional Ultrasound; Low Birth Weight; Gestational age.

Disclosure: The authors have no financial interest to declare in relation to the content of this article. The Article Processing Charge was paid for by the authors.

Authorship: All authors have a substantial contribution to the article. 
Therefore, it is important to keep in mind that neonates with a birth weight less than the $10^{\text {th }}$ percentile will be SGA, but not an IUGR if there are no features of malnutrition, and a neonate with a birth weight greater than the $10^{\text {th }}$ percentile will be an IUGR despite being an AGA if the infants have features of malnutrition at birth. ${ }^{4}$

Risk factors for fetal growth restriction include constitutionally small mothers, poor maternal nutrition, social deprivation, maternal and fetal infections, congenital malformations, chromosomal aneuploidies, disorders of cartilage and bone, drugs with teratogenic and fetal effects, vascular disease, renal disease, pregestational diabetes, chronic hypoxia, anemia, placental and cord abnormalities, infertility, extrauterine pregnancy, anti-phospholipid antibody syndrome, genetics and multiple fetuses. ${ }^{5}$

The placenta links mother and fetus by indirect interaction with maternal blood to allow the exchange of gases and nutrients with fetal capillary blood within connective tissue at the villous core. Fetal and maternal blood is not normally mixed in the placenta. There is also a paracrine system that links mother and fetus through the placenta. This is an important arrangement for communication between fetus and mother and maternal immunological acceptance of conceptus. ${ }^{6}$

Adequate fetal growth and subsequent normal birth weight depend on the efficient delivery of nutrients from the mother to the fetus and therefore requires normal uterine perfusion, normal transplacental exchange of nutrients and waste, and normal umbilical blood flow. ${ }^{7}$

Sonographically, the normal placenta is homogenous and 2 to $4 \mathrm{~cm}$ thick, lies against the myometrium and indents into the amniotic sac. The retro placental space is a hypoechoic area that separates the myometrium from the placenta's basal plate and measures less than 1 to $2 \mathrm{~cm}$. During prenatal sonographic examinations, placental location and relationship to the internal cervical os are recorded. The umbilical cord is also imaged, its fetal and placental insertion sites examined, and its vessels counted. ${ }^{5}$

The placental thickness is measured transabdominally by placing the ultrasound transducer perpendicularly to the plane of the placenta, in the area of the cord insertion at the third trimester, at term the placenta is approximately $3 \mathrm{~cm}$ thick at the cord insertion. ${ }^{8}$

An abnormally decreased placental weight has been linked to increased perinatal complications, including intrauterine fetal demise (IUFD) and fetal growth restriction (IUGR). Despite its promise, determining placental weight prenatally using threedimensional systems is time-consuming and requires expensive technology and expertise. Placental weight can be accurately predicted by two-dimensional ultrasound with volumetric calculations. This method is simple, rapid, and accurate, making it practical for routine prenatal care, as well as for high-risk cases with decreased fetal movement and IUGR. Routine estimated placental volume (EPV) surveillance may decrease the rates of perinatal complications and unexpected IUFD. ${ }^{7}$

This study was conducted to assess the role of measurement of placental thickness and diameter in the third trimester using two-dimensional ultrasound in the determination of low birth weight.

\section{PATIENT AND METHODS}

Type of the study: Observational prospective study was conducted between 15 October 2019 and 10 June 2019. This study was carried out at Sayed Galal University Hospital and Damanhour Teaching Hospital on "400" uncomplicated pregnant women who attended the outpatient clinic at Sayed Galal University Hospital and Damanhour Teaching Hospital, two-dimensional ultrasound measurement of placental thickness and diameter was done to assess its role in the determination of low birth weight.

Duration of follow up: measurement of placental thickness and diameter maximally one week before delivery and the $1^{\text {st }}$ weight of the baby was measured during the first hour of life to assess the role of measurement placental thickness and diameter in the determination of low birth weight

Inclusion criteria: Patients aged between 20 and 30 years, singleton viable pregnancies and gestational age from 27 weeks till the time of delivery.

Exclusion criteria: Abnormally situated placenta and placental anomalies and patients with pregestational and gestational diabetes mellitus.

\section{Collecting data:}

Every patient eligible for the study is submitted for: Fully informed verbal and written consent, complete detailed medical and obstetric history recorded as a standard paper form and including patient age, height, weight, parity, date of last normal menstrual period, medical disorders and surgical intervention.

\section{Intervention:}

Every patient eligible for the study is submitted for a detailed ultrasound examination by twodimensional ultrasound to determine. Fetal gestational age at time examination by measuring biparietal diameter, femur length, and abdominal circumference. Expected fetal weight $(\mathrm{EFW})$ by Hadlock's formula (abdominal circumference, biparietal diameter, and femur length). The placental site, diameters, and thickness, and ultrasound scan was repeated every two weeks till delivery.

\section{Outcome data:}

Primary outcome: Birth weight is detected within the first hour of delivery.

Secondary outcome: Neonatal status and morbidity including APGAR score, neonatal distress or 
neonatal death and admission to the neonatal intensive care unit (NICU). Gestational age at the time of delivery and fetal congenital anomalies.

\section{Statistical analysis:}

Recorded data were analyzed using the statistical package for social sciences, version 20.0 (SPSS Inc., Chicago, Illinois, USA). Quantitative data were expressed as mean \pm standard deviation (SD). Qualitative data were expressed as frequency and percentage.
The following tests were done: Independentsamples t-test of significance was used when comparing two means. Chi-square $\left(\mathrm{x}^{2}\right)$ test of significance was used to compare proportions between two qualitative parameters. The confidence interval was set to $95 \%$ and the margin of error accepted was set to 5\%. The p-value was considered significant as the following: Probability (P-value); $\mathrm{P}$-value $<0.05$ was considered significant. $\mathrm{P}$-value $<0.001$ was considered highly significant. P-value $>0.05$ was considered insignificant.

RESULTS

\begin{tabular}{||l|l|c|c||}
\hline \multicolumn{2}{||c|}{} & $\begin{array}{c}\text { Number } \\
\text { “n=400” }\end{array}$ & Percent \\
\hline \multirow{2}{*}{ Parity } & Primigravida & 152 & 38.0 \\
\cline { 2 - 4 } & Multigravida & 248 & 62.0 \\
\hline \multirow{2}{*}{ Mode of delivery } & VD & 211 & 52.8 \\
\cline { 2 - 4 } & CS & 189 & 47.2 \\
\hline Variables & Mean \pm SD & Range \\
\hline Maternal age (years) & $25.7 \pm 2.3$ & $20.0-30.0$ \\
\hline
\end{tabular}

Table 1: Maternal age, parity, and mode of delivery among the studied cases

Table 1 shows maternal age, parity, and mode of delivery among the studied cases. Primigravida parity was $152(38 \%)$, Multigravida parity was $248(62 \%)$, delivery with VD was $211(52.8 \%)$ and delivery with CS was $189(47.2 \%)$. Age ranged from 20-30 with a mean value of $25.7 \pm 2.3$.

\begin{tabular}{|c|c|c|c|}
\hline & & $\begin{array}{l}\text { Number } \\
\text { "n=400" }\end{array}$ & Percent \\
\hline \multirow{2}{*}{ Fetal sex } & Male & 202 & 50.5 \\
\hline & Female & 198 & 49.5 \\
\hline \multirow{14}{*}{ GA } & 27 & 2 & 0.5 \\
\hline & 28 & 2 & 0.5 \\
\hline & 29 & 3 & 0.8 \\
\hline & 30 & 2 & 0.5 \\
\hline & 31 & 2 & 0.5 \\
\hline & 32 & 4 & 1.0 \\
\hline & 33 & 3 & 0.8 \\
\hline & 34 & 4 & 1.0 \\
\hline & 35 & 3 & 0.8 \\
\hline & 36 & 4 & 1.0 \\
\hline & 37 & 25 & 6.3 \\
\hline & 38 & 113 & 28.3 \\
\hline & 39 & 151 & 37.8 \\
\hline & 40 & 82 & 20.5 \\
\hline \multicolumn{2}{|l|}{ Variables } & Mean \pm SD & Range \\
\hline \multicolumn{2}{|l|}{ GA (weeks) } & $38.3 \pm 2.1$ & $27.0-40.0$ \\
\hline
\end{tabular}

Table 2: Fetal gestational age (GA) and sex among the studied cases.

Table 2 shows that fetal gestational age (GA) and sex among the studied cases. Males were 202(50.5\%) and females were 198(49.5\%). The most frequent increase was in week 39 with 151(37.8\%) followed by week 38 with $113(28.3 \%)$. GA weeks ranged from $27-40$ with a mean value of $38.3 \pm 2.1$. 


\begin{tabular}{|l|c|c|}
\hline Variables & $\mathbf{r}$ & $\mathbf{P}$ \\
\hline Maternal age & -0.040 & 0.429 \\
\hline GA & 0.850 & $<\mathbf{0 0 1} *$ \\
\hline Placental thickness & 0.492 & $<\mathbf{0 . 0 0 1 *}$ \\
\hline Placental diameter & 0.116 & $\mathbf{0 . 0 2 0} *$ \\
\hline Biparietal diameter & 0.732 & $<\mathbf{0 0 1} *$ \\
\hline Femur length & 0.706 & $<\mathbf{0 0 1} *$ \\
\hline Abdominal circumference & 0.634 & $<\mathbf{0 0 1} *$ \\
\hline
\end{tabular}

Table 3: Correlation between neonatal weight and other variables

Total $=400$. Pearson correlation. $*$ Significant

Table 3 shows that there were significant positive correlations between neonatal weight and GA, Placental diameter, Placental thickness, Biparietal diameter, Femur length \& Abdominal circumference $(\mathrm{P}<0.05)$, while there was no statistically significant difference regarding maternal age $(\mathrm{P}>0.05)$.

\begin{tabular}{||l|c|c|c||}
\hline Measures & $\begin{array}{c}\text { Primigravida } \\
(\mathbf{N = 1 5 2})\end{array}$ & $\begin{array}{c}\text { Multigravida } \\
(\mathbf{N = 2 4 8})\end{array}$ & ${ }^{{ }^{\mathbf{p}}}$ \\
\hline GA & $38.2 \pm 2.2$ & $38.4 \pm 2.0$ & 0.420 \\
\hline Placental thickness & $36.0 \pm 2.3$ & $35.8 \pm 2.2$ & 0.384 \\
\hline Placental diameter & $196.0 \pm 22.6$ & $196.2 \pm 21.1$ & 0.941 \\
\hline Biparietal diameter & $9.4 \pm 0.6$ & $9.4 \pm 0.6$ & 0.193 \\
\hline Femur length & $7.4 \pm 0.6$ & $7.5 \pm 0.5$ & 0.244 \\
\hline Abdominal circumference & $34.3 \pm 3.1$ & $34.7 \pm 3.0$ & 0.212 \\
\hline Neonatal weight & $3.1 \pm 0.5$ & $3.1 \pm 0.5$ & 0.188 \\
\hline
\end{tabular}

Table 4: Comparison according to parity regarding fetal and placental measures

${ }^{\wedge}$ Independent t-test.

Table 4 shows that there was no statistically significant difference according to parity regarding fetal and placental measures.

\begin{tabular}{|c|c|c|c|}
\hline Measures & $\begin{array}{c}\text { Male } \\
(\mathrm{N}=\mathbf{2 0 2})\end{array}$ & $\begin{array}{l}\text { Female } \\
(\mathrm{N}=198)\end{array}$ & ${ }^{\wedge} \mathbf{p}$ \\
\hline GA & $38.5 \pm 2.0$ & $38.1 \pm 2.2$ & 0.135 \\
\hline Placental thickness & $35.9 \pm 2.3$ & $35.8 \pm 2.2$ & 0.527 \\
\hline Placental diameter & $196.3 \pm 21.8$ & $195.9 \pm 21.7$ & 0.829 \\
\hline Biparietal diameter & $9.5 \pm 0.5$ & $9.3 \pm 0.6$ & 0.001* \\
\hline Femur length & $7.6 \pm 0.5$ & $7.4 \pm 0.6$ & 0.001* \\
\hline Abdominal circumference & $35.0 \pm 2.9$ & $34.1 \pm 3.1$ & $0.003 *$ \\
\hline Neonatal weight & $3.2 \pm 0.5$ & $3.0 \pm 0.6$ & $\wedge<0.001 *$ \\
\hline
\end{tabular}

Table 5: Comparison according to fetal sex regarding fetal and placental measures

${ }^{\wedge}$ Independent t-test. *Significant

Table 5 shows that there was no statistically significant difference according to fetal sex regarding placental measures $(\mathrm{P}>0.05)$. There was a statistically significant difference according to Biparietal diameter, femur length, abdominal circumference \& Neonatal weight $(\mathrm{P}<0.05)$. Fetal measures were significantly higher among males.

\begin{tabular}{|c|c|c|c|c|}
\hline \multicolumn{2}{|c|}{ Variables } & $\begin{array}{l}\leq 2.5 \mathrm{~kg} \\
(\mathrm{~N}=33)\end{array}$ & $\begin{array}{l}>2.5 \mathrm{~kg} \\
(\mathrm{~N}=367)\end{array}$ & $\mathbf{P}$ \\
\hline \multicolumn{2}{|c|}{ Maternal age (years) } & $25.9 \pm 2.6$ & $25.7 \pm 2.3$ & $\wedge 0.513$ \\
\hline \multirow{2}{*}{ Parity } & Primigravida & $16(48.5 \%)$ & $136(37.1 \%)$ & \multirow{2}{*}{ \#0.195 } \\
\hline & Multigravida & $17(51.5 \%)$ & $231(62.9 \%)$ & \\
\hline \multirow{2}{*}{ Fetal sex } & Male & $9(27.3 \%)$ & $193(52.6 \%)$ & \multirow{2}{*}{ \#0.005* } \\
\hline & Female & $24(72.7 \%)$ & $174(47.4 \%)$ & \\
\hline \multicolumn{2}{|l|}{ Fetal GA } & $33.0 \pm 3.5$ & $38.8 \pm 0.9$ & ${ }^{\wedge}<0.001 *$ \\
\hline \multicolumn{2}{|c|}{ Placental thickness (mm) } & $32.4 \pm 3.7$ & $36.2 \pm 1.8$ & $\wedge<0.001 *$ \\
\hline \multicolumn{2}{|c|}{ Placental diameter (mm) } & $186.7 \pm 22.0$ & $196.9 \pm 21.5$ & ^0.009* \\
\hline \multicolumn{2}{|c|}{ Biparietal diameter (cm) } & $8.2 \pm 1.0$ & $9.5 \pm 0.3$ & $\wedge<0.001 *$ \\
\hline \multicolumn{2}{|c|}{ Femur length $(\mathrm{cm})$} & $6.4 \pm 0.9$ & $7.6 \pm 0.4$ & $\wedge<0.001 *$ \\
\hline \multicolumn{2}{|c|}{ Abdominal circumference $(\mathrm{cm})$} & $29.2 \pm 4.8$ & $35.0 \pm 2.3$ & $\wedge<0.001 *$ \\
\hline
\end{tabular}

Table 6: Comparison according to neonatal weight regarding different variables

${ }^{\wedge}$ Independent t-test. \#Chi square test. *Significant 
Table 6 shows that cases with low birth weight significantly had lower Fetal GA, Placental thickness, Placental diameter, Biparietal diameter, Femur length, and abdominal circumference as well as significantly less frequent males.

\begin{tabular}{|l|c|c|c|c|c|}
\hline Factors & $\boldsymbol{\beta}$ & SE & $\mathbf{P}$ & $\mathbf{9 5 \%}$ CI & $\mathbf{R}^{\mathbf{2}}$ \\
\hline Constant & -5.746 & 0.273 & $<\mathbf{0 . 0 0 1} *$ & $-6.283--5.209$ & \\
\cline { 1 - 5 } GA (week) & 0.209 & 0.008 & $<\mathbf{0 . 0 0 1} *$ & $0.194-0.224$ & \multirow{2}{*}{0.752} \\
\hline Placental thickness (mm) & 0.022 & 0.007 & $\mathbf{0 . 0 0 2} *$ & $0.008-0.035$ & \\
\hline Male sex & 0.164 & 0.027 & $<\mathbf{0 . 0 0 1} *$ & $0.110-0.218$ & \\
\hline
\end{tabular}

Table 7: Regression model for the prediction of neonatal weight among the studied cases

及: Regression coefficient, SE: Standard error, CI: Confidence interval, *significant, $\mathrm{R}^{2}$ : Coefficient of determination.

Table 7 shows a regression model for the prediction of neonatal weight among the studied cases. GA, placental thickness and male sex were significant factors that increase weight. The following model can explain $75.2 \%$ of weight variability: Weight $(\mathrm{kg})=-5.746+0.209 * \mathrm{GA}($ week $)+0.022 *$ Placental thickness $(\mathrm{mm})+0.164$ (if male). This model is for gestational age from week-27 to week-40.

\section{DISCUSSION}

Our study was conducted to assess the role of measurement of placental thickness and diameter in the third trimester using two-dimensional ultrasound in the determination of low birth weight.

This study was carried out at Sayed Galal University Hospital and Damanhour Teaching Hospital on "400" uncomplicated pregnant women who attended the outpatient clinic at Sayed Galal University Hospital and Damanhour Teaching Hospital, two-dimensional ultrasound measurement of placental thickness and diameter was done to assess its role in the determination of low birth weight.

The primary outcome of this study was birth weight detection within the first hour of delivery. While the secondary outcome was neonatal status and morbidity including APGAR score, neonatal distress or neonatal death and admission to the neonatal intensive care unit (NICU). Gestational age at the time of delivery. Fetal congenital anomalies. Mode of delivery.

In the results of our study, it was found that there was a positive significant correlation between the neonatal weight and gestational age, the mean neonatal weight at gestational age 27 was less than 1 $\mathrm{kg}$ and increased gradually till the 40 weeks gestational age show the heights weigh more than 3.5 $\mathrm{kg}$. This result was an agreement with a study carried out by Topcu et al. ${ }^{9}$. This study provides important information on birth weight for gestational age of all newborns delivered during the study period in a tertiary research hospital in Turkey. This is the largest population study from Turkey describing the association between birth weight and gestational age. This study describes the highly significant association of birth weight with gestational age ${ }^{9}$.

Nagpal et al. ${ }^{10}$, reported the birth weights, birth length, and head circumference of 4750 newborns from Turkey. This study had a relatively small sample size and utilized data collected from 11 different hospitals; also, they started birth weight data collection from 28 weeks of gestation. Although we collected birth weight data from the 24th week in our study, we used data only from the 28th week in figure 6 to compare our results with that of Nagpal et al. ${ }^{10}$

In our study the placental thickness show a significant positive correlation with the neonatal weight, Also the placental thickness show an increasing with gestational age, at 27 weeks gestational age the placental thickness was $24.5 \mathrm{~mm}$, and increased till 37 weeks gestational age to be 37.7 $\mathrm{mm}$ and the change was minor in the last 3 weeks of gestational age. In the study carried out by Owen et al. ${ }^{11}$, the results of this study presented a significant relationship between average gestational age and placental thickness in the second trimester and third trimester. ${ }^{11}$

In Sadler ${ }^{12}$ study, we observed increased incidence of perinatal morbidity in terms of low Apgar scores and increased NICU admissions in those with placental thickness $4.0 \mathrm{~cm}$ at 36 weeks, and our study showed an increased incidence of low-birth-weight babies in women with the thick placenta.

In agreement with our results, Mathai et al. ${ }^{13}$, found a fairly linear increase in mean placental thickness with gestational age was observed in correlation analysis studies conducted to determine the relationship between placental thickness and gestational age.

In our study, significant positive correlations between placental thickness and estimated fetal weight in the second and third trimesters (p\0.05) in a non-IUGR group were also demonstrated. A positive correlation, with increasing placental volume with increasing gestational age, was also observed, but it remained reduced in the growth-restricted fetus. The usefulness of this relationship between placental thickness and growth parameters is that subnormal placental thickness for gestational age may be the earliest indication of fetal growth retardation. In Mathai et al., ${ }^{13}$ the study, a significant positive correlation is seen between placental thickness and the ultrasonographic gestational age in days in both groups (p-value of 0.01).

Mathai et al. ${ }^{13}$, studied the correlation of placental thickness in 498 subjects with ultrasonographic gestational age and fetal outcome by dividing them 
into two groups - Group A (outcome fetal weight $12500 \mathrm{~g}, \mathrm{n}=122$ ) and Group B (fetal weight [2500 g, $\mathrm{n}=376$ ). They found a positive correlation between placental thickness and ultrasonographic gestational age in both groups. They also concluded that placental thickness in Group A between 26 and 27 weeks and 30 and 31 weeks had lower mean values of $2.48 \pm 0.063 \mathrm{~cm}$ (p value 0.05 ) and $2.76 \pm$ 0.552 (p-value $=0.05)$ as compared to $3.04 \pm 0.25$ and $3.13 \pm 0.183 \mathrm{~cm}$ in Group B ${ }^{13}$.

The results of our study show a highly significant positive correlation between maternal age and biparietal diameter, also the biparietal diameter shows an increase by the gestational age, at 27 weeks gestational age the biparietal diameter was $6.7 \mathrm{~cm}$ and increase till 40 weeks gestational age to be 9.8 $\mathrm{cm}$. It was found a positive significant correlation between neonatal weight and femur length and abdominal circumference.

In agreement with our study, Sharma et al., ${ }^{14}$ they study the correlation of placental thickness with gestational parameters like femur length, Biparietal thickness, Head circumference, abdominal circumference. Placental thickness has a significantly high correlation with all the gestational parameters. The linear regression model of placental thickness with each of the parameters is presented in this study and they found a positive significant correlation between fetal weight and biparietal diameter, femur length and abdominal circumference. ${ }^{14}$

Fetal size has been measured using four growth parameters including Fetal Biparietal Diameter (BPD) and Head Circumference (HC), fetal Abdominal Circumference (AC); and Fetal Femur Length (FL). These four measurements have been combined in various ways, to estimate fetal weight and growth. The most commonly used equations for estimated fetal weight are the Hadlock Formula and the Shephard Formula. The present study shows that there are significant relations between $\mathrm{HC}, \mathrm{AC}, \mathrm{FL}$, BPD, and Placental thickness. Therefore using Placental thickness will be a great value in fetal biometric parameters and growth assessment. ${ }^{14}$

Karthikeyan et al., ${ }^{3}$ measured the maximum mean Placental thickness in the 3rd trimester as $35.81 \mathrm{~mm}$ and reported a significant correlation of it with the gestational age of the fetus.

In our study, the linear model of placental thickness with gestational age was used to predict the neonatal weight among the studied group, the accuracy of this equation was $75.2 \%$. Also, Sharma et al., ${ }^{14}$ predict an equation to predict the neonatal weight with accuracy near $85.0 \%$ by using the same variables and Fetal Biparietal Diameter (BPD) and Head Circumference (HC), fetal Abdominal Circumference (AC); and Fetal Femur Length (FL).

These four measurements have been combined in various ways, to estimate fetal weight and growth The most commonly used equations for estimated fetal weight are the Hadlock Formula and the Shephard Formula. The present study shows that there are significant relations between $\mathrm{HC}, \mathrm{AC}, \mathrm{FL}$, $\mathrm{BPD}$, and Placental thickness. Therefore using
Placental thickness will be a great value in fetal biometric parameters and growth assessment. ${ }^{2,15}$

\section{CONCLUSION}

The result of this study shows a strong positive correlation between neonatal weight and placental thickness, so placental thickness measured at the level of umbilical cord insertion can be used as an accurate sonographic indicator in the assessment of fetal weight.

Placental thickness below the 10th percentile was found to be associated with low-birth-weight infants and poor Apgar score and increased nursery admissions.

\section{REFERENCES}

1. Afrakhteh M, Moeni A, Taheri $\mathrm{M}$, et al. Correlation between placental thickness in the second and third trimester and fetal weight. Rev Bras Ginecol Obstet., 2013; 35(7):317-22.

2. Agwuna KK, Eze CU, Ukoha PO, et al. Relationship between sonographic placental thickness and gestational age in normal singleton fetuses in Enugu, Southeast Nigeria. Ann Med Health Sci Res., 2016; 6(6):335-40.

3. Karthikeyan T, Subramaniam RK, Johnson W, et al. Placental thickness \& its correlation to gestational age $\&$ fetal growth parameters- a cross-sectional ultrasonographic study. J Clin Diagn Res., 2012; 6(10):1732-5.

4. Azpurua H, Funai EF, Coraluzzi LM, et al. Determination of placental weight using twodimensional sonography and volumetric mathematic modeling. Am J Perinatol., 2010; 27(2):151-5.

5. Balla E, Ahmed M, Ayad C et al. Prediction of fetal growth by measuring the placental thickness using ultrasonography. Journal of Gynecology and Obstetrics, 2014; 2(2): 26-31.

6. Cunningham FG, Leveno KJ, and Bloom SL. Fetal growth disorders. Williams Obstetrics, 2014; 2:872-900.

7. Guzeloglu-kayisli O, Kayisli UA, and Taylor HS. The role of growth factors and cytokines during implantation: endocrine and paracrine interactions. Semin Reprod Med., 2009; 27(1):62-79.

8. Kurtoglu S, Hatipoglu N, Mazıcioglu MM, et al. Body weight, length and head circumference at birth in a cohort of Turkish newborns. J Clin Res Pediatr Endocrinol., 2012; 4:132-9.

9. Topcu H, Guzel A, Ozgu E, et al. Birth weight for gestational age: A reference study in a tertiary referral hospital in the middle region of Turkey. Journal of the Chinese Medical Association, 2014; 77: 578-582.

10. Nagpal K, Mittal P and Grover S. Role of Ultrasonographic Placental Thickness in Prediction of Fetal Outcome: A Prospective Indian Study. The Journal of Obstetrics and 
Gynecology of India, 2018; 68(5):349-354.

11. Owen P, Ogah J, Bachmann LM, et al. Prediction of intrauterine growth restriction with customized estimated fetal weight centiles. BJOG, 2003; 110:411-415.

12. Sadler TW. Longman's medical embryology. 9th edition. Baltimore, MD: Lippincott Williams and Wilkins, 2004; Pp. 117- 48.

13. Mathai M, Singla C, Nittala $P$, et al. Placental thickness: Its correlation with ultrasonographic gestational age in normal and intrauterine
Obst. and Gyn.

growth-retarded pregnancies in the late second and third trimester. The Journal of Obstetrics and Gynecology of India, 2013; 63(4):230-233

14. Sharma D, Shastri S, Farahbakhsh N, et al. Intrauterine growth restriction-part 2. J Martin Fetal Neonatal Med., 2016; 0(0):1-12.

15. Zhang X, Joseph KS, Cnattingius S, et al. Birth Weight Differences between Preterm Stillbirths and Live Births. Analysis of Population-based Studies from the U.S. and Sweden. BMC Pregnancy Childbirth, 2012; 12 (119): 15-19. 